\title{
A Study on the New E-commerce Development Patterns Based on
}

\section{WeChat}

\author{
Bo Liu \\ School of Foreign Languages, China West Normal University, Nanchong City, Sichuan \\ Province, 637002, China
}

Keywords: mobile Internet; WeChat; e-commerce; O2O

\begin{abstract}
As the rapid development of computer technology, network technology and communication technology, e-commerce has been integrated into all aspects of modern life. The rise of WeChat platform and the maturity of development technology promote electrical business to transform from traditional e-commerce to mobile e-commerce. Based on account of the study and practical experience of the author, this paper firstly analyzed the development background of WeChat e-commerce, and then summarized the its advantages, and finallyp put forward the issues and coping strategies of WeChat mobile e-commerce.
\end{abstract}

\section{Introduction}

As an entrance of mobile Internet, WeChat has more and more users, and the number of the users presents fission growth rate. According to the Tencent announced the report of the second quarter of 2016 and the interim, the data displays that the number of active users of combined months reached 806 million, and it increased 34\% on year-on-year basis. The applications of WeChat, such as two-dimensional code and shake make it has strong e-commerce potential. In addition, although the scale of WeChat users is large, it has a close communication attribute as well as a strong effect of interactive communication. Moreover, more people spend odd time using WeChat, and the cumulative time is long. The study showed that $3 / 4$ of mobile search would lead to follow-up activities, and the purchase of goods accounted for $24 \%$. Finally, the LBS function of WeChat can realize the "one-stop" service of e-commerce, so the users can directly search nearby businesses, or they can directly access to the information of the geographical locations after searched to these businesses. On this basis, Tencent began to promote O2O closed loop system of "two-dimensional code + account number system + LBS + payment + relation chain". So whether WeChat can bring rewards for the operators and where is the outlet? This paper will be based on the characteristics and advantages of WeChat, starting from the analysis of the profit patterns of it, and then talk about the feasibility of profit pattern of "WeChat + e-commerce" as well as expand the future development space of Tencent on the new thing, WeChat.

\section{The Development Background of WeChat E-commerce Based on Mobile Internet}

Mobile Internet is a network platform that the users can use mobile phones, tablet computers and other intelligent devices for data communication through the mobile communication technology and Internet technology. It is a combination of mobile communication technology and Internet technology, and it has some characteristics, such as wide coverage area, convenient and immediate, etc. The e-commerce based on mobile Internet is the business activity by mobile Internet, while the traditional e-commerce is the business activity which in the traditional Internet and the PC environment. As far as the popularity of 3G network and the rise of $4 \mathrm{G}$ network, as well as the effect of low prices of intelligent terminal equipment and other factors, mobile e-commerce has had a huge impact to the traditional e-commerce. 
The vice president of global supply chain of Amazon Yu Gang pointed out that mobile e-commerce is not only an electronic commerce evolution, and e-commerce transforms from PC to mobile devices, mobile facilities only rely on some of its advantages, such as at anytime or anywhere, portable and freewheeling as well as use its a large number of innovative features, such as its voice, scanning, image recognition and so on, can make different users enjoy the convenience of e-commerce whenever and wherever possible. In the current mainstream mobile Internet social networking platform, the WeChat platform of Tencent Inc is the most successful platform of China. Through the open system of WeChat friends, the numerous social circles and contacts circles become the e-commerce platforms of service enterprises business. The business field of WeChat official accounts comes down to sales, communications, finance, banking, government, logistics, media, etc. Jingdong, Amazon, Suning, Gome and other traditional business giants vied for the WeChat platform, and they want to take advantage of the superiority of WeChat that it has a certain extent of users scale. WeChat is gradually becoming a major commercial trading platform, and the development opportunity brought by WeChat mobile e-commerce to the field of e-commerce should not be overlooked.

\section{The Analysis of WeChat E-commerce's Advantages}

WeChat has a broad group advantages. WeChat has developed rapidly since its birth, and it occupies a place of mobile Internet and become the application which has the highest occupancy in the current domestic market as well as the highest usage rate of users. As a comprehensive mobile social networking platform which has hundreds of millions of users, WeChat has occupied the first throne of domestic mobile social media. With the popularity of smart phone and the development of $4 \mathrm{G}$ network, more and more businesses start to be optimistic about WeChat platform. WeChat has a stronger user viscosity and more accurate marketing function, and in enterprises' eyes, it has become a huge marketing tool.

At present, WeChat has successfully made offline access to the mobile Internet, and it has a huge user groups, with the addition of WeChat is based on the location of the LBS function, it has a large advantage in the realization of one-stop e-commerce services. Through the basic orientation of the geographical position, the users can have a basic understand of business positions when selecting businesses. When the businesses considering the problems such as advertising, they can also have better target groups of users. On this basis, businesses and WeChat businesses can make full use of the function to have realizations and developments.

Making use of the information transmission characteristics of Circle of Friends and Instant Messaging function diffusion. The WeChat platform is instant messaging platform, its most prominent features are real-time, fast and efficient communication which makes it is easy to realize the convenient and punctual communication between enterprises and customers, without the constraints of geographical and time. Moreover, making use of the technology characteristics that acquaintances can transmit and pay close attention to each other in "circle of friends", WeChat improve the speed of information transmission as well as expand the scope of the spread.

The commercial purchase conversion rate, user viscosity and attention are high. Compared with the WEB business platform or native APP of e-commerce, WeChat has the advantage of the characteristics of convenient communication and interaction. According to statistics, in the rate of transformation from the intention to purchase, WeChat marketing can reach more than $8 \%$. Base on the business official platforms or corporate accounts or service accounts, at the time of enterprises promote the products and enhance the images, they realize the autonomy and self recognition of customers. This way makes it easier for firms to find or enhance the potential consumer groups, and the recognition and viscosity of the users can be 
further improved.

To facilitate the data analysis and mining Based on big data. Relying on the cloud platform of Tencent Inc, WeChat stored a large amount of historical data for clients, and it also provided a paltform for the enterprise for their own historical data and formed the resources which are convenient to analyze and clear up. Enterprises can clear up those data through browsing tracks, using habit and other dissemination behaviors of clients, and they can also extract and purify the messages that users published and reprinted in "Circle of Friends" and set up an analysis model of behavior and psychological data of the clients; the functions, such as "Scan QR Code"can make different managements of the goods that customers searched; the function of "WeChat Payment" can form the deal data of customers; through "My Collection", they can make a deep analysis on the consumption views and values of customers; the data analysis of official accounts can set up brands and audience management models. These big data collection can provide effective support for the e-commerce to carry out accurate advertising marketing and develop business strategies.

\section{The Problems and Countermeasures of WeChat Mobile E-commerce}

The mobile payment technology has security threats. The security threats come from the intelligent terminal of mobile communication. The safety protection in mobile phones and other mobile devices with built-in is very limited, and once loss of data means that the disclosure of user sensitive personal data, making illegal users can visit the payment system through the data resources of mobile terminal, such as digital certificates and transaction authentications, etc. Therefore, the function of payment on WeChat needs some groups reach a same standard including Tencent, Tenpay, network operators and banks. And they improve the mobile payment firewall technology, data encryption technology, digital signature technology, authentication technology and anti-virus technology, to ensure the security of users of WeChat and create mobile payment protection chain formed by the polices, banks, merchants and third party payment companies. In this way, they can provide systematic security solutions and effectively protect the payment security.

The platform development model should be standardized and unified. The current business development mode of WeChat is diversified, someone make secondary developments of WeChat's public accounts and let them become WeChat malls, or someone make the second level domain name website analysis graft to the WeChat system, to achieve to interchange with the HTML5 mall, or others send the addresses in Circle of Friends to link to the WeChat stores. The development model has not a final stable model. Therefore, at the time of opening the interface, WeChat should unify the business development mode and establish uniform standards of access service as well as unify the ecological environment standard of WeChat platform, to build a better and more convenient e-commerce platform for medium and small businesses use the mobile Internet.

WeChat payment function still needs further development. WeChat payment scenarios only include more than ten kinds, such as mobile phone recharge, financier, Didi taxi and selected goods, etc. It is far less than Alipay on the product number and payment function. The e-commerce payment function must be attached to the trading scenario can work, and this scenario is not limited to online consumption. At present, WeChat has cooperated with the offline businesses. Through grasping of important offline consumer scenarios, WeChat can expand their territory gradually and build new mobile $\mathrm{O} 2 \mathrm{O}$ electricity consumption scenarios.

Must reinforce the deep experiences of WeChat users. The traditional e-commerce consumption patterns have been popular and have large customers groups, and the mobile 
e-commerce is still in its infancy and it needs a long run-in time in the future. At present, WeChat needs to encourage and stimulate consumers to have deep experiences of mobile e-commerce, and gradually occupied the e-commerce market. Therefore, in order to achieve the aim of rapidly occupy the market, WeChat must improve the experiences of users, and have a reasonable control of consumers' expectations as well as enhance the actual experiences of consumers, such as the quality of the products, shopping experiences, after-sales services and so on. On special circumstances, WeChat can also send coupons, envelopes, discounts and other surprises to enhance the experiences of users, and then enhance the user's perceptions of mobile e-commerce, and strive to be convenient, smooth and natural.

\section{Summary}

Through the process of birth and development of WeChat mobile e-commerce, we must see that as the commercial trend of WeChat, it has made the Tencent brand extends from the social attribute of the original gradually, and in the near future, WeChat mobile e-commerce must can be compared with the mature Taobao. WeChat will also combine online platforms and offline businesses by different methods, and it will break the barriers of online and offline, and introduce the $\mathrm{O} 2 \mathrm{O}$ service life of excellent enterprises. According to the payment function, WeChat will create a good WeChat service life ecosystem, and thus promote the developments of other industries.

\section{References}

[1] Ding Naipeng, Li Na. Research on the development of WeChat mobile e-commerce [J]. future and development, 2015, 03: 20-24+45.

[2] Yu Peiying. The discussion of WeChat e-commerce model [J]. software, 2013, 10: 124-125+135.

[3] Chen Meiqing. The discussion of the development of WeChat e-commerce under the mobile Internet [J]. cooperative economy and technology, 2016, 06: 62-63.

[4] Chen Xiaoqing, Zhao Cheng, Hao Wei, Yang Xingwen. The imaginations of P2P mobile e-commerce model of WeChat platform [J]. Hebei enterprises, 2016, 02: 61-62.

[5] Jiang Meiling, Li Suqi. Analysis of e-commerce marketing model based on WeChat [J]. technological economic market, 2016, 02: 74-75.

[6] Liu Yali. Analysis of the advantages of mobile e-commerce's development based on WeChat in China [J]. Modern business, 2016, 20: 80-81.

[7] Tao Ling. A discussion based on WeChat's e-commerce model [J]. technology outlook, 2016, 29: 286. 